\title{
Molecular Detection of Theileria Annulata in Egyptian Buffaloes and Biochemical Changes Associated with Particular Oxidative Changes
}

\author{
A. E. F. Ali ${ }^{1}$, M. E. I. Radwan,", \\ ${ }^{1}$ Department of clinical pathatholgy, Vet. Hospital Benha University \\ ${ }^{2}$ Department of Infectious Diseases, Vet. Hospital Benha University
}

\begin{abstract}
This investigation is performed on 100 buffaloes native Breed in Kaliobia governorate Egypt aged from 1 -3years, these animals suffered from fever $\left(41^{\circ} \mathrm{C}\right)$ enlargement lymph node, inappetence, pale mucous membrane, increase lacrimation, emaciation and corneal opacity in progressive stages when these animals were subjected to microscopic examination the degree of parasitaema was recorded as the percentage of infected red blood cells in 1000red blood cell counted .We report the detection of Theileria annulata by PCR in blood samples obtained from buffaloes supposed to be infected. The assay employs primers specific for the gene encoding Theileria annulata 185RNA biochemical changes associated with Theileria annulata in these buffaloes particular emphasis to the oxidative stress the reduce TAC level may reflect adecrease in antioxidant capacity. Blood collected from all animals on EDTA to microscopic examination and PCR to determine type of Theileria.
\end{abstract}

Keywords Theileria, PCR, Oxidative Changes

\section{Introduction}

Theileria annulata, a protozoan parasite of cattle and domestic buffalo (Bubalus bubalis). It causes tropical Theileriosis, a disease which is present in northern Africa and southern Europe, extending through the middle East, India, and southern Russia into China (Uilenberg, 1981). Dignosis of clinical T. annulata infection in bovine is usually based on the detection of macroschizonts in Giemsa-stained lymph node biopsy smears. In addition, serological tests such as the indirect immumoflurescent antibody test (IFA) can be used to detect circulating antibody either piroplasms or cultured macroschizonts as the antigen (Pipano and Cahana, 1969). However, cross-reactivity with antibodies directed against other Theileria species limits the specificity of IFA (Burridge et al., 1974). Moreover, antibodies tend to disappear in long-term carriers, whereas Theileria piroplasms persist.

Therefore, animals with negative serological test may be still infected Theileria annulata represent a major threat for Egyptian water buffaloes, causing significant economic losses as well as reduced production clinical picture that may be mistaken with other diseases. Stained thin blood

* Corresponding author:

mervatbio@yahoo.com (M. E. I. Radwan)

Published online at http://journal.sapub.org/als

Copyright (C) 2011 Scientific \& Academic Publishing. All Rights Reserved film lymph node smear may be useful to detect Theileria in animals but PCR has allowed the development of sensitive diagnostic assays for Theileria annulata (Tanaka et al., 1993).

Here, we report the use of PCR for sensitive and specific amplification of T. annulata DNA from blood samples obtained from buffaloes primers were derived from the gene encoding Theileria annulata 18s RNA. Results PCR amplified DNA products were analyzed by agarose gel electrophoresis and confirmed by sequencing and blast on the NCBI website.

A significant feature of the disease is hemolytic anemia (Gill et al., 1977; Omer et al., 2002). The cause of hemolytic anemia is immune mediated hemolysis which is indicated by the presence of a hamagglutinin (Hooshmand- Rad, 1976). Although various evidence has been presented to explain the mechanism of the anemia, the exact underlying mechanism is currently unknown (Shiono et al., 2004). reported that oxidative damage to RBCs may contribute to the pathogenesis of anemia in bovine tropical theileriosis (Asri Rezaei \& Dalir-Naghadeh ,2006). Oxidative stress may result from an imbalance between reactive oxygen species (ROS) and antioxidants levels (Lightboy et al. 2001). The erythrocyte has several intracellular modes of protection against oxidation, For example, it carries enzymes such as superoxide dismutase, glutathione peroxidase, and catalase capable of disarming oxidizing radicals, and it contains antioxidants such as reduced glutathione (GSH) and vitamin E 
(El Deeb and Younis ). Erythrocytes are particulary susceptible to an oxidative damage as a result of high polyunsaturated fatty acid content in their membranes and high concentration of oxygen and haemoglobin, the latter being a potentially powerful promoter of oxidative processes (Carrell et al., 1975) . Increasing of parasitaemia rate in cattle infected with Theileria annulata, an increase in erythrocyte osmotic fragility and a decrease in SOD activity occurred, the antioxidant status of tissues can be described by the analysis of single components in the defense systems against ROS, as well as by the determination of total antioxidant (TAC). (Cimen, 2008). Nazifi et al., (2008). The present study aimed to:

1. Detection of theileria annulata in buffaloes

2. assess the effect of theileria annulata infection on the antioxidant mechanism of RBCs.

\section{Material and Methods}

This experiment was performed on 100 buffaloes from native breed in Kaluobia Governorate ages range from 13 years from different location all animals were clinically examined with special attention to signs related to Theileria infection samples collected from all animals Apparently Healthy and infected samples.

The blood samples we collected from Juglar vein by sterile sharp nudle with wide pore samples were collected in clean and dry test tube containing EDTA as anticoagulant for blood smear and PCR analysis.

\section{Blood Film}

Three thin blood film were prepared for every sample and left in air to dry and fixed in absolute methyle alcohol for 1-2min. staining with freshly filtered and diluted Giemsa stain for $30-45 \mathrm{~min}$ then washed with distal water to remove excess of stain after that the slides were left to dry then but one drap afcider oil and examined under oil immersion lens according to (Coles, 1986). Examination of blood film for Theileria $1 / 4^{-1 / 2}$ inch from end of the film and transferred from one slide to other (cross-section method) to give constant and representive examination according to (Barrent, 1965) animal be considered negative if the three slides were negative.

\section{DNA Extraction\& PCR}

\subsubsection{DNA Extraction from Blood}

The DNA was extracted from each sample by chloroform- isoamyl extraction method (All buffers used according to Sambrook et al. (1989).

Blood samples typically were obtained as $1 \mathrm{ml}$ of whole blood stored in EDTA vacutainer tubes. To each $1 \mathrm{ml} \mathrm{sam}$ ple, add $0.8 \mathrm{ml} 1 \mathrm{X} \mathrm{SSC}$ buffer, and mix. Centrifuge for 1 minute at $12,000 \mathrm{rpm}$ in a microcentrifuge. Remove $1 \mathrm{ml}$ of the supernatant and discard into disinfectant. Add $1 \mathrm{ml}$ of $1 \mathrm{X}$ SSC buffer, vortex, and centrifuge as above for 1 minute, and remove all of the supernatant. Add 375 ul of $0.2 \mathrm{M} \mathrm{NaOAc}$ to each pellet and vortex briefly. Then add 25 ul of $10 \%$ SDS and $5 \mathrm{ul}$ of proteinase $\mathrm{K}(20 \mathrm{mg} / \mathrm{ml} \mathrm{H} 2 \mathrm{O})$ (Sigma P-0390), vortex briefly and incubate for 1 hour at $55^{\circ} \mathrm{C}$. Add $120 \mathrm{ul} \mathrm{phenol/chloroform/isoamyl} \mathrm{alcohol} \mathrm{and}$ vortex for 30 seconds. Centrifuge the sample for 2 minutes at $12,000 \mathrm{rpm}$ in a microcentrifuge tube. Carefully remove the aqueous layer to a new $1.5 \mathrm{ml}$ microcentrifuge tube, add $1 \mathrm{ml}$ of cold $100 \%$ ethanol, mix, and incubate for $15 \mathrm{mi}-$ nutes at $-20^{\circ} \mathrm{C}$. Centrifuge for 2 minutes at $12,000 \mathrm{rpm}$ in a microcentrifuge. Decant the supernatant and drain. Add 180 ul 10:1 TE buffer, vortex, and incubate at $55^{\circ} \mathrm{C}$ for $10 \mathrm{mi}-$ nutes. Add $20 \mathrm{ul} 2 \mathrm{M}$ sodium acetate and mix. Add $500 \mathrm{ul}$ of cold $100 \%$ ethanol, mix, and centrifuge for 1 minute at $12,000 \mathrm{rpm}$ in a microcentrifuge. Decant the supernatant and rinse the pellet with $1 \mathrm{ml}$ of $80 \%$ ethanol. Centrifuge for 1 minute at 12,000 rpm in a microcentrifuge. Decant the supernatant, and dry the pellet in a Speedy-Vac for $10 \mathrm{mi}-$ nutes (or until dry). Resuspend the pellet by adding $200 \mathrm{ul}$ of 10:1 TE buffer. Incubate overnight at 37C, vortexing periodically to dissolve the genomic DNA. Store the samples at $-20^{\circ} \mathrm{C}$.

\subsubsection{PCR}

Specific PCR has been used to detect the gene encoding 18sRNA for T. annulata within DNA extracts of the suspected animals for infection. Forward and reverse primers were designated using NCBI website and the contribution of genebank, the primers sequences were:

Forward: CGGAAGGGCACCACCAGGC;

Reverse GCATCAGTGTAGCGCGCGTG

The PCR master mix was comprised of PCR buffer (300 $\mathrm{mM}$ Tris, $75 \mathrm{mM}$ ammonium sulfate, $\mathrm{pH}$ 9.0), $2.5 \mathrm{mM}$ $\mathrm{MgCl}, 400 \mu \mathrm{M}$ dNTPs, $20 \mathrm{pmol}$ of each primer, and $2 \mathrm{U}$ $\mu \mathrm{l}-1$ taq DNA polymerase. The PCR cycling parameters were one cycle of $94^{\circ} \mathrm{C}$ for $5 \mathrm{~min}, 35$ cycles of $94^{\circ} \mathrm{C}$ for 30 $\mathrm{s}, 52^{\circ} \mathrm{C}$ for $30 \mathrm{~s}$ and $72^{\circ} \mathrm{C}$ for $1 \mathrm{~min}$, with a final extension step of $72^{\circ} \mathrm{C}$ for $10 \mathrm{~min}$. PCR products were analyzed by electrophoresis on $1.5 \%$ agarose gel and documented with documentation system.

\subsubsection{Reduced Glutathione (R.GSH)}

The activity of R.GSH was carried out using commercially available test kits, according to the method described by Beutler et al., (1963).

\subsubsection{Total Antioxidant Capacity (TAC)}

The activity of TAC was carried out using commercially available test kits, according to the method described by Koracevic et al., (2001).

\section{Results}


A. E. F. Ali et al:: Molecular Detection of Theileria Annulata in Egyptian Buffaloes and Biochemical Changes Associated With Particular Oxidative Changes

Table 1 showed that different clinical signs of Theileriosis in Egyptian buffaloes as fever, Enlargement superficial lymph nodes emaciated, Lacrimation, Respiratory manifestation, Anorexia, skin lesion, diarrhoea, corneal opacity, Nasal discharge pale mucous membrane and decrease milk yield corneal opacity, and lacrimation while in Table 2 showed that TAC and GSH. In uninfected buffaloes and buffaloes infected with theileria annulata.

Table 1. Clinical examination to signs related Theileria annulata iN buffaloes.

\begin{tabular}{|c|c|c|}
\hline Clinical signs & $\begin{array}{c}\text { Number of affected ani- } \\
\text { mals to total sick ones }\end{array}$ & $\%$ \\
\hline Fever & $90 / 100$ & $90 \%$ \\
\hline Enlargement of L.N. & $20 / 100$ & $70 \%$ \\
\hline Facrimation & $20 / 100$ & $20 \%$ \\
\hline $\begin{array}{c}\text { Respiratory manifesta- } \\
\text { tion }\end{array}$ & $20 / 100$ & $20 \%$ \\
\hline Anorexia & $9 / 100$ & $9 \%$ \\
\hline Skinlesion & - & - \\
\hline Diarrhoea & $1 / 100$ & $1 \%$ \\
\hline Corneal opacity & $20 / 100$ & $20 \%$ \\
\hline Nasal discharge & $2 / 100$ & $2 \%$ \\
\hline Pale mucous membrane & $70 / 100$ & $70 \%$ \\
\hline Decreased milk & $19 / 100$ & $19 \%$ \\
\hline
\end{tabular}

Table 2. Mean $\pm \mathrm{SE}$ of GSH and TAC in uninfected cattle and cattle infected with Theileria annulata.

\begin{tabular}{|c|c|c|}
\hline & $\begin{array}{c}\text { GSH } \\
\text { Mmol/l }\end{array}$ & $\begin{array}{c}\text { TAC } \\
\text { Mmol/l }\end{array}$ \\
\hline Control & $2.83 \pm 0.10$ & $3.52 \pm 0.21$ \\
\hline Infected cattle & $1.37 \pm 0.03 * * *$ & $1.66 \pm 0.2 * * *$ \\
\hline
\end{tabular}

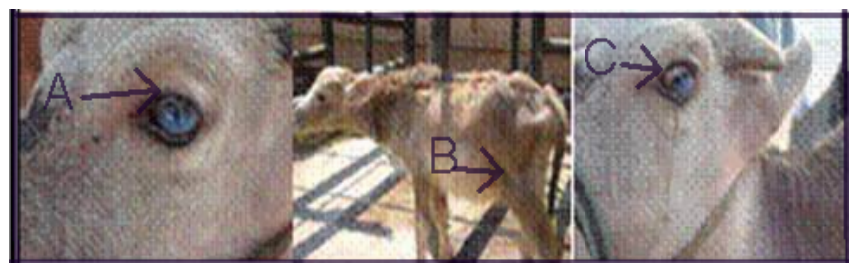

Figure 1. clinical signs of theileriosis in buffalo: A corneal opacity, B Emaciated and enlargement in L.N, C Lacrimation.

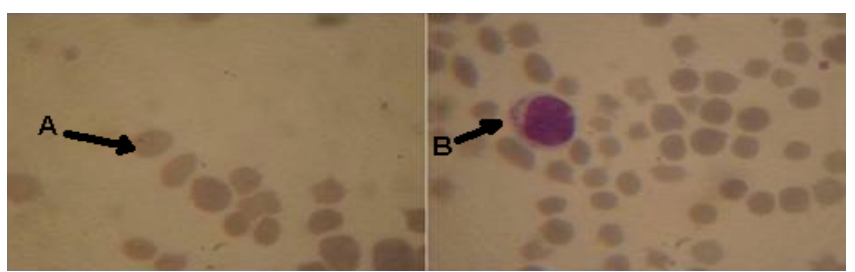

Figure 2. Microscopic examination of giemsa stain blood film showed that: A round, oval piroplasms in erythrocytes, B intralymphocytic shizont of theileria and change in erythrocytes shape.

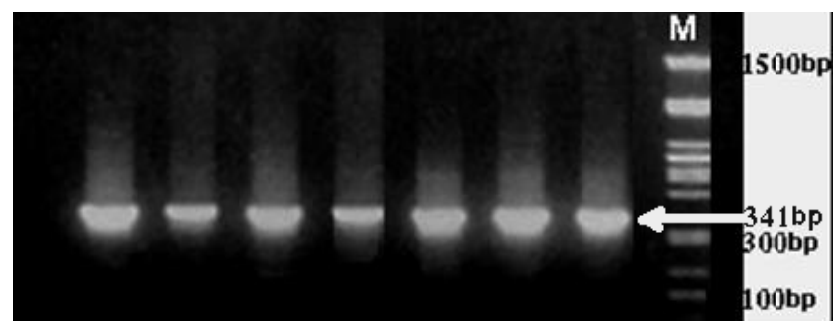

Figure 3. Detection of $\mathrm{T}$. annulata in blood samples by PCR, results from $1.5 \%$ agarose gel electrophoresis
Figure 1 showed that corneal opacity, enlargement in lymph, emaciated and lacrimation node. Figure. 2. Microscopic examination to 100 animals showed intralymphocytic shizonts and piroplasm form in erythrocytes in blood film with Gemsia stained

Figure. 3 Results obtained in the PCR assay showed 35 out of 50 samples $(70 \%)$ infected with theileria annulata therefore oxidative stress associated with Theileria annulata were determined in 35 infected buffaloes and recorded results.

Statistical analysis: Data were analyzed using T-Test as described by (Petrie and Waston 1999).

Identification of DNA sequence of T. annulata

Blast queries of the resulted sequenced nucleotides indicated the identity with $\mathrm{T}$. annulata.positive for $\mathrm{T}$. annulata, with the expected band molecular weight 341 base pair in 50 animals only. The dignosis must be confirmed by PCR because Theileria spp. resembles each other so differentiation was occurred by DNA assays.

\section{Discussion}

Infection by Theileria parasites limits the movement of buffaloes between countries and can result in production losses as (decrease in milk yield and weight loss) and high mortality insusceptible animals. Because this disease is most sever in recently introduce animals, they are a constrict on the importation of new breeds or improved stock, tropical theileriosis (infection with Theileria annulata) consider from greatest economic disease of buffaloes in Egypt this results is agreement with Osman SA., Al-Gaabary MH (2007).

Concerning the clinical signs, the affected buffaloes with T. annulata were suffered from fever, Enlargement lymph node, Lacrimation Respiratory manifestation, Anaroxia Diarrhoea, Corneal opacity and decreased milk as recorded with (El-Deeb Younis 2009) . Microscopic examination of Giemsa stained blood film revealed T. annulata, the organism is intracellular erythrocytes piroplasma form oval or round and intralymphocytic shizonts this agreement with (Ramazan and Ugur, 2006) .Piroplasma occasionally occur in blood of carrier animals but many cases they can't be detected by direct examination, the diagnosis must be confirmed by detecting shizonts. Blood smear examination proved to limited value in diagnosis of sub acute or chronic cases in this study only 50 animals were positively identified by microscopic examination out of 100 animals with different stage of clinical signs this result in agreement with Herbart W.J. and Iumsden H.R (1976) who found that when parasites number less than 2, 500, 000 parasites per $\mathrm{ml}$ present in blood samples microscopic detection is not feasible PCR.

The prevalence of theileria annulata infection in Egyptian buffaloes is high therefore, this study throw the light on oxidative stress state of such infection. Decrease level of R.GSH and TAC in affected buffaloes may be an indicator 
of high oxidative stress in Theileriosis. The oxidative stress appears when the production of free radicals and reactive metabolites of oxygen exceeds their safe disposal by antioxidant mechanisms this investigation is agreement with (El Deeb and Younis ).

With the availability of sequenced parasite genes and PCR, it is possible to detect parasites within samples of blood (Tanaka et al., 1993). In this study, we developed a PCR assay for improved detection of T. annulata in blood samples from carrier buffalloes. Previously, we amplified a 341-bp fragment by using a primer pair from all blood samples taken from animals suspected to be infected.

Using 18sRNA primer, the expected 341-bp product was amplified from blood samples and the specificity of this fragment was confirmed by DNA product sequencing. Successful amplification of $T$. annulata from Kalubia region indicates that the targeted gene sequence is conserved within T. annulata.

Exploitation of both the highly conserved and hypervariable sequences genes like 18sRNA permits designing of a platform primers capable of early detection and specific pathogen identification in a single rapid detection platform. PCR analyses, permitting identification of definitive pathogen characterization of the species. Diagnostic accuracy of our assay was evaluated against conventional light microscopy-based methods. This assay may be a useful early diagnostic for T. annulata.

In the present study, a significant decrease in erythrocyte TAC and GSH levels were detected in buffalloes infected with Theileria annulata in contrast to the healthy control animals. In buffalloes infected with $T$. annulata, the antioxidant levels of RBCs decreased during the progression of anaemia this results are agreement with (Murat Guzel et.al. 2007). The findings in this study may suggest the alteration in antioxidative and oxidative balance due to oxidative stress and ROS generation in the course of theileriosis. This alteration may be due to a decrease in the levels of enzymatic and non-enzymatic antioxidants, which are the component of antioxidant-defence system this record as (Rezai and Dalir- Naghadeh, 2006).

\section{Conclusions}

The diagnosis of theileria spp must be confirmed by PCR because there is a great morphological similarity among theileria spp. The decreased levels of erythrocytic GSH and TAC in cattle infected with Theileria annulata may indicate oxidative damage to RBCs.

\section{REFERENCES}

[1] Asri Rezaei S. and B. Dalir-Naghaded, (2006). Evaluation of antioxidant status and oxidative stress in cattle infected with Theileria annulata. Veterinary Parasitology, 142, 179-186
[2] Beutler E., Duron O., Kelly MB. J. Lab Clin Med.(1963),61, 882

[3] Burridge M. J., C. G. D. Brown, and C. D. Kimber. (1974). Theileria annulata: cross reactions between a cell culture schizont antigen and antigens of East African Theileria species in the indirect fluorescent antibody test. Exp. Parasitol. $35: 374-380$

[4] Burridge M. J., C. G. D. Brown, and C. D. Kimber. (1974). Theileria annulata: cross reactions between a cell culture schizont antigen and antigens East African THeileria species in the indirect fluorescent antibody test. Exp. Parasitol. $35: 374-380$

[5] Carrell R. W., Winterbourn C. C. and Rachmilewitz, E. A. (1975): Br. J. Haematol. 30:259-264

[6] Cimen M. Y. (2008): free radical metabolism in humen erythrocytes. Clin. Chem Acta,390,1-11

[7] Eveunt Ceslava Kairane, Ivivaher and Mihkel Zilmer (2008). Red blood cell and whole blood glutathione redox status in endurance-trained men following aski marathon Journal of sports science and medicine 7, 344-349

[8] Gill B. S., Y. Bhattacharyulu and D. Kaur, (1977). Symptoms and pathology of experimental bovine tropical theileriosis ( theileria annulata). Annales de parasitologie, 52, 597-608

[9] Herbert J. and Lusden H. R. (1976). Trypanosome brucei: a Rapid matching methods for estimating the host parasitaemia exp. parasitol. 40,427-431

[10] Hooshmand-Red, p. (1976). the pathogenesis of anaemia in theileria annulate infection. Reseach in Veterinary Science, 20,324-329

[11] Koracevic D., Koracevic G., et al., Clin Pathol. 54, 356-361 (2001)

[12] Lightboy J. H., Stevenson L. M., Jackson F., Donaldson k., Jones D. G.( 2001): Comparative aspects of plasma antioxidant status in sheep and goats, and the influence of experimental abomasal nematode infection. J Comp Pathol, 124, 192-199

[13] Murat Guzel Tunay Kontas Askar, Galipkaya, Emine Atakisi, and Gulcan ErBil Avci (2008): Serum sialic acids total antioxidant capacity, and adenosine deaminase activity in cattle with Theileriosis and anaplasmosis. Bill vet inst pulway 52, 227-230

[14] Nazifi S., M. Razavi, M. Mansourian B. Nikahval and M. Moghaddam (2008). Studies on correlation among parasitemia and some hemolytic indices in two tropical diseases (theileriosis and anaplasmosis) in Fars province of Iran. Tropical animal health and Production, 39, 41-48

[15] Omer O. H., El-Malik K. H., Mahmoud O. M., E. Haroun M. A. Hawas S. and Magzoub D., (2002) Haematological profiles in pure bred cattle naturally infected with theileria annulata in Saudia Arabia. Veterinary Parasitology, 107, 161168

[16] Osman SR, Al-Gaabary MH. (2007). Clinical, haematological and therapeutic studies on tropical Theilerosis in water buffaloes (Bubalus bubalis) in Egypt. Vet. Parasitol. 146(34):337-40

[17] Pipano E., and Cahana M.. (1969). Fluorescent antibody test 
for the serodiagnosis of Theileria annulata. J. parasitol. $55: 765$

[18] Pipano E., and Cahana M.. (1969). Fluorescent antibody test for the serodiagnosis of Theileria annulata. J. Parasitol. 55: 765

[19] Rezai S. A. and Dalir-Naghadeh B. (2006): Evaluation of antioxidant status and oxidative stress in cattle naturally infected with Theileria annulata. Vet parasitol, 142, 179-186

[20] Sambrook J., Fritsch. and Maniatis T. (1989). Molecular cloning: a laboratory manual cold spring Harbour laboratory press, New York

[21] Sambrook J.; Fritsch, E.F. and Maniatis T.(1989). Molecular Cloning: a Laboratory Manual. Cold Spring Harbour Laboratory Press, New York

[22] Shiono H., Yagi Y., Kumar M. Yamanaka M. and Chikayama Y. (2004). Accelerated binding of autoantibody to red blood cells with increasing anemia in cattle experimentally infected with Theileria sergenti. Journal of Veterinary Medicine B,
$51,39-42$

[23] Tanaka M., Onoe S., Matsuba T. Katayama S., Yamanaka M., Yonemichi H., Hiramatsu K., Baek B.K., Sugimoto C. and Onuma M. (1993). Detection of Theileria sergenti infection in cattle by polymerase chain reaction amplification of parasite-specific DNA. J. Clin. Microbiol. 31:2565-2569

[24] Uilenberg G. (1981). Theilerial species of domestic livestock, p. 4-37. in A.D. Irvin, M.P. Cunningham, and A.S. Young (ed.), Advances in the control of Theileriosis martinus nijhoff. The Hague, the Netherlands

[25] Uilenberg G. (1981). Theilerial species of domestic livestock, p. 4-37. In A. D. Irvin, M. P. Cunningham, and A. S. Young (ed.), Advances in the control of theileriosis. Martinus Nijhoff, The Hague, the Netherlands

[26] El-Deeb W. M. and Younis E. E. (2009): Clinical and biochemical studies on Theileria annulata in Egyptian buffaloes (Bublus bublis) with particular emphasis on oxidative stress and ketosis relationship cercetari agronomic in moldova vol. XL11, No. 3(139) 